The BDJ News section accepts items that include general news, latest research and diary events that interest our readers. Press releases or articles may be edited, and should include a colour photograph if possible. Please direct your correspondence to the News Editor, Arveen Bajaj at the BDJ, The Macmillan Building, 4 Crinan Street, London N19XW or by email to bdj@bda.org

\section{A step towards revalidation}

The General Dental Council (GDC) is calling for views on plans to strengthen its existing continuing professional development (CPD) scheme for dentists and introduce compulsory CPD for all dental care professionals. These plans are a first step towards a revalidation system, which the GDC intends to deliver incrementally and which will require all dental professionals to show on a regular basis that they are fit to remain on the GDC's registers.

The GDC will be inviting views at each stage as it develops revalidation. This current consultation is the first in a series and covers proposals to enhance the compulsory CPD scheme for dentists, including the introduction of compulsory core subject areas, by 1 January 2007, and introduce compulsory CPD for dental care professionals from 2008.

The GDC is keen to hear the views of as wide a range of people as possible - patient groups, members of the public, all members of the dental team, dental employers, healthcare providers, and others are encouraged to contribute.

The consultation document is available on the GDC website at www.gdcuk.org. The deadline for responses is Thursday 16 March 2006.

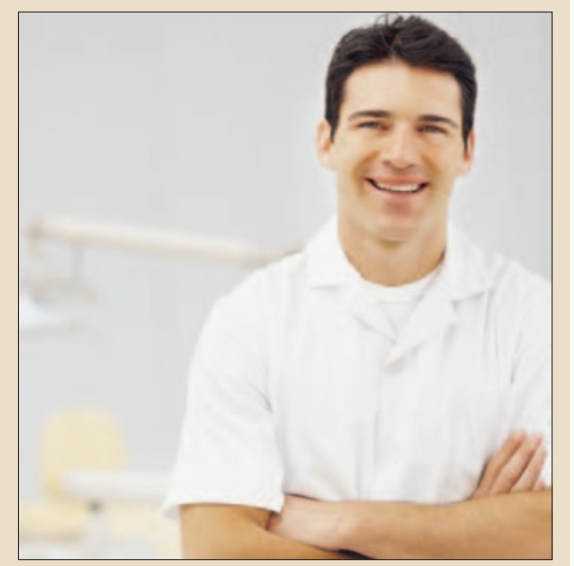

\section{Celebrating BDJ volume 200}
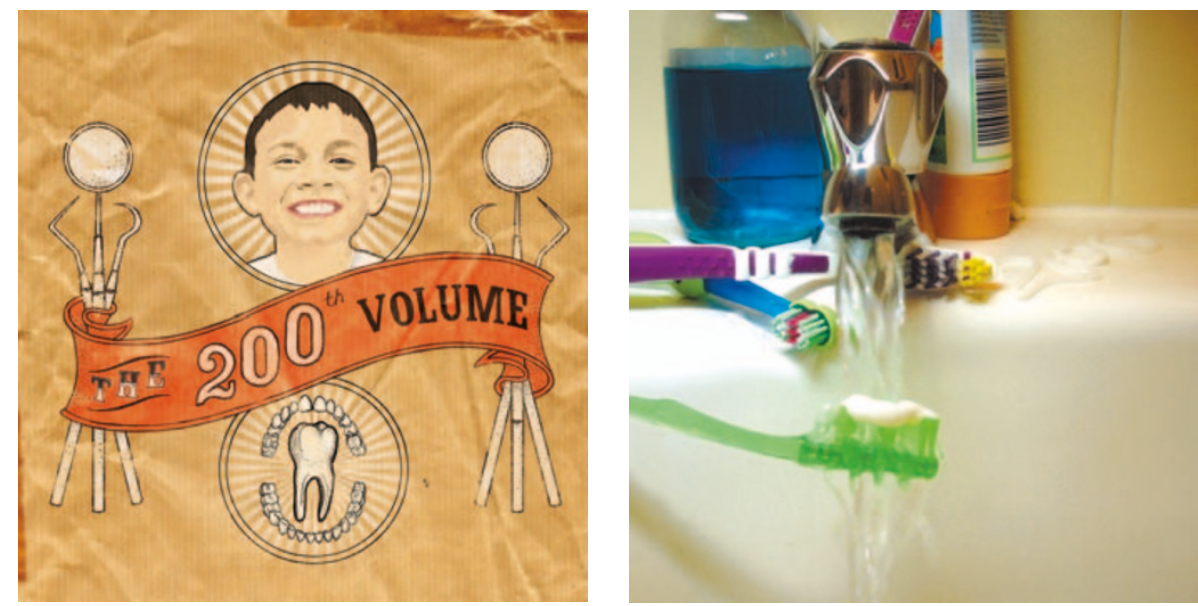

Since its inception in 1906, the $B D J$ has changed and developed immensely and this year sees the publication of its 200th volume, a milestone we have marked with a series of 12 special cover images. Twelve upcoming artists have been commissioned to design a cover for the Journal reflecting the combined themes of 200 and oral health. The aim was to present a unifying theme for the whole volume while allowing each issue to feature a different and very individual piece of artwork. The result is a striking and varied series of images celebrating 200 volumes of the $B D J$, as highlighted here by the cover images for issues one and two.

\section{More proof of links between gum disease and heart disease}

The Journal of Dental Research has just published the results of a study showing that treatment of gum disease may reduce the risk of cardiovascular disease. Researchers from Australia (Sydney Dental Hospital and Royal North Shore Hospital) and Norway (University of Oslo) provide strong evidence linking periodontal disease to an increased risk of developing blood clots, which could lead to the onset of heart attack and stroke. In recent years, many studies have linked periodontal disease to increased cardiovascular risk, although the reasons for this link have not been fully explained, nor has it been proven that the link is a direct causal one. One explanation is that inflammation and infection have also been related to increased atherosclerosis and cardiovascular risk. Periodontal disease is the most common chronic infection in humans. Individual participants who were involved in the trial had blood tests before and after treatment of gum disease that was so severe that all their teeth had to be extracted. The blood tests were for blood-clot risk factors and signs of inflammation. The average level of factors fell when the gum infection was eradicated, suggesting that the risk of heart attacks and clots in the future had reduced. This also indicates that inflammation in the mouth has a measurable effect in the bloodstream, and therefore the rest of the body. The researchers are currently studying the relationship between gum and heart disease in people with less severe periodontal disease who do not need to have all their teeth extracted. 


\section{Mystery of world's strangest tooth solved}

Martin Nweeia, a researcher at the Harvard School of Dental Medicine (HSDM), has answered a marine science question that has eluded the scientific community for hundreds of years: why does the narwhal have an 8-foot-long tooth emerging from its head, and what is its function? Nweeia, a clinical instructor in restorative dentistry and biomaterials sciences at HSDM, presented his conclusions at the 16th Biennial Conference on the Biology of Marine Mammals in San Diego last month. The narwhal has a tooth, or tusk, which emerges from the left side of the upper jaw and is an evolutionary mystery that defies many of the known principles of mammalian teeth. The tooth's unique spiral, the degree of its asymmetry to the left side, and its odd distribution among most males and some females are all unique expressions of teeth in mammals. Nweeia has discovered that the narwhal's tooth has hydrodynamic sensor capabilities. Ten million tiny nerve connections tunnel their way from the central nerve of the narwhal tusk to its outer surface.

Though seemingly rigid and hard, the tusk is like a membrane with an extremely sensitive surface, capable of detecting changes in water temperature, pressure, and particle gradients. Because these whales can detect particle gradients in water, they are capable of discerning the salinity of the water, which could help them survive in their Arctic ice environment. It also allows the whales to detect water particles characteristic of the fish that constitute their diet. 'Why would a tusk break the rules of nor-

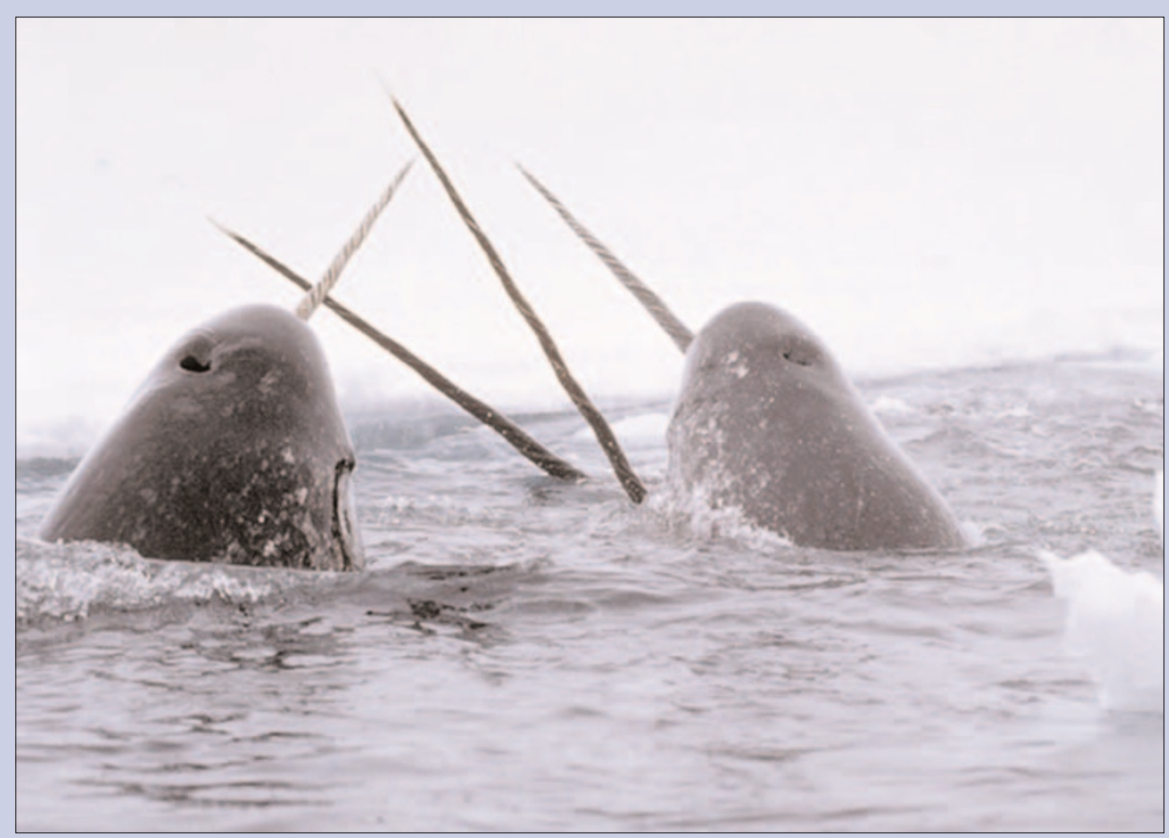

Photo: Glenn Williams mal development by expressing millions of sensory pathways that connect its nervous system to the frigid arctic environment?' says Nweeia. 'Such a finding is startling and indeed surprised all of us who discovered it.'

In the past, many theories have been presented to explain the tooth's purpose and function, none of which have been accepted as definitive. One of the most common is that the tooth is used to display aggression between males, who joust with each other for social hierarchy. Another is that the tooth is a secondary sexual characteristic, like a peacock's feathers or a lion's mane.

Nweeia's findings point to a new direction of scientific investigation. Results from the team's research already has practical applications; studies about the physical makeup of the tusk, which is both strong and flexible, provide insight into ways of improving restorative dental materials.

\section{Winners of the GDC Prize for Professionalism award}

The General Dental Council (GDC) has announced this year's winners of the GDC Prize for Professionalism award. The annual Prize for Professionalism aims to recognise the achievements of student dental professionals in the UK.

Sponsored by the GDC Charitable Trust, it is awarded to students who have demonstrated professionalism in areas such as patient care, clinical governance, team working, communication skills, reliability, integrity and knowledge.

The GDC invited all UK dental schools, schools of dental hygiene and schools of dental therapy with undergraduates to pick a winner each from among their students. The winners of the Prize for Professionalism Award 2005 are shown in the table, right.

The winners will receive their prize money and certificates at an award ceremony in early 2006.

\begin{tabular}{|c|c|c|c|c|}
\hline Institution & Dentist & Dental therapist & Dental hygienist & $\begin{array}{l}\text { Combined hygienist } \\
\text { \& therapist }\end{array}$ \\
\hline Aldershot & - & - & Stacey Barker & - \\
\hline Belfast & Aine Campbell & - & Fiona Taggart & - \\
\hline Birmingham & Hannah Cherry & - & - & Claire Hall \\
\hline Bristol & Sarah Toone & - & Amy Williams & - \\
\hline Cardiff & William Rhymer & David Pook & Jennifer Pearce & - \\
\hline Dundee & Samuel Rollings & $\begin{array}{l}\text { Joyce Drummie } \\
\text { \& Sandra Forbes* }\end{array}$ & $\begin{array}{l}\text { Course discontinued } \\
\text { after } 2004\end{array}$ & - \\
\hline Edinburgh & - & - & Lindsey Goodhead & - \\
\hline Glasgow & Robert Pendreigh & - & - & Gillian Marshall \\
\hline Leeds & Elizabeth A. Zdziech & - & - & Susan Timpson \\
\hline Liverpool & $\begin{array}{l}\text { Bal Balaggan \&t } \\
\text { Suzie Carew O'Donnell' }\end{array}$ & & - & Kathryn Dobson \\
\hline London Barts & Huda Albasri & & & Ann Lally \\
\hline London Eastman & & Sarah Lendon & Katy Episkopos & - \\
\hline London GKT & N. J. Opie & - & S Shingley & - \\
\hline Manchester & $\begin{array}{l}\text { Sarah-Jane } \\
\text { Johnstone }\end{array}$ & - & - & Kaye Shepherd \\
\hline Newcastle & Simon Stone & - & Angela Hadwin & - \\
\hline Salford & - & - & - & Ann Fearon \\
\hline Sheffield & Emma Clark & - & - & Sarah Thirkill \\
\hline
\end{tabular}

* Where a school has chosen two winners for one category, the prize money will be divided between them. - means that the school does not offer that course. 


\section{Appointments and promotions at the School of Dentistry, University of Manchester}

Manchester Dental School has recently made several key appointments to senior academic positions and has consolidated its research and teaching activities. These appointments are Iain Pretty to senior lecturer in restorative dentistry, Richard Oliver to senior lecturer in medical, surgical and diagnostic sciences, and Marco Esposito to senior lecturer in oral maxillofacial surgery. Iain Mackie has been promoted to professor of dental education and Martin Tickle to professor of dental public health and primary care. The head of the school, professor Kevin 0'Brien, says, 'These appointments reflect the support of the University in the rapidly improving School of Dentistry, which is increasing its profile in teaching and research'.

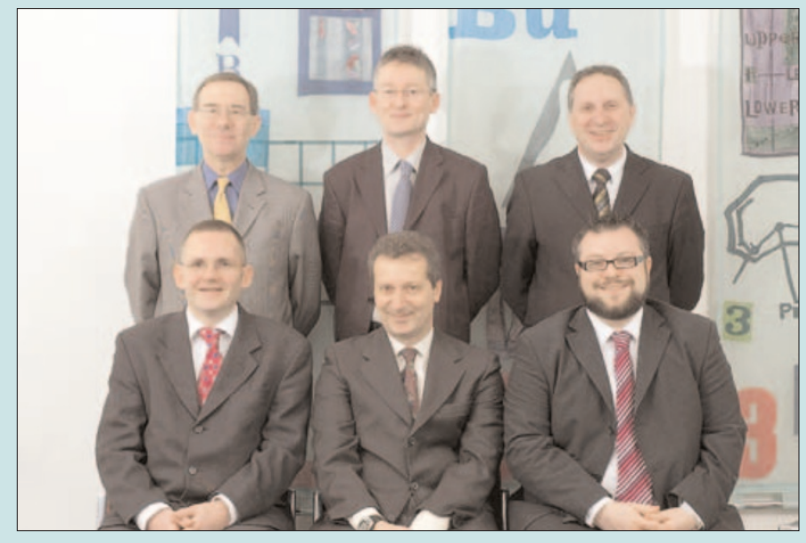

Back row (left to right): lain Mackie, Kevin O'Brien, Martin Tickle. Front row: Richard Oliver, Marco Esposito and lain Pretty

\section{Getting to the root of a complaint about private dentistry}

A dental patient complained about the cost of a filling. His dentist, meanwhile, claimed that the patient was clearly told, in advance of the treatment, what the cost of the filling could be. Another dentist suggested that her patient had unrealistic expectations when he complained that his treatment took too long. These cases are based on real examples of complaints about private dental treatment, previously referred to the General Dental Council. But how should they be resolved? Next year they could be heard by a regional volunteer panel of the new Dental Complaints Service.

The complaints panels will be part of a simple, flexible and fast complaints procedure based on common sense, to be used if the dentist's own complaints system and informal mediation have not managed to resolve matters. Where breakdowns in communication occur - specifically over private dental treatment - the Dental Complaints Service will aim to resolve them. The panels, which will be held as locally as possible to where the complaint originated, will consist of two lay members and a dental professional. Lay volunteers are not expected to be knowledgeable about dentistry but to use their common sense and seek advice on clinical matters from the dental professional. Panellists must be fair and open-minded; be able to question and weigh up different sides of an issue; and be able to express themselves clearly and confidently. Crucially, volunteer panellists will be provided with training so that they feel comfortable with their role before they are asked to sit on their first panel.

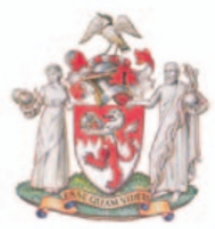

\section{General Dental Council}

To find out more about volunteering to join a complaints panel, call $08456120 \quad 540$ up and funding the Dental Complaints Service in line with its guidance to dental care professionals to put patient's interests first and act to protect them. (local rate). The GDC is setting
February

BDA Careers Day 2006

Logan Hall

Venue: Institute of Education, London

Date: Friday 10th February 2006

Young Dentists' Conference

London

Date: Saturday 11th February 2006

Tel. 08700102043

March

Carriere Distalizer Barcelona Seminar

Barcelona, Spain

Date: 17 to 18th March 2006.

DB Orthodontics Limited

Tel. 08007833552

email sales@dbortho.com

Bollard MiniPlate Implant \& Distraction

Study Day

Professor Hugo De Clerck \&t Dr Zvi Laster Venue: Royal Surrey County Hospital

Date: 21st March 2006

$8.30 \mathrm{am}$ to $5: 00 \mathrm{pm}$

Freephone 08007833552

email sales@dbortho.com

Freefax 08007833363

April

British Society for the Study of Prosthetic Dentistry Annual Conference

Venue: Carlton Hotel, Edinburgh

Date: 9-11th April 2006

Email:bookings@bsspd.org

www.bsspd.org

May

10th European Congress Dentomaxillofacial

Radiology

Venue: Provinciehuis

Leuven, Belgium

Date: 31 May -2 June 2006

www.10ecdmfr.be

July

82nd Congress of the European Orthodontic Society

Venue: Hofburg Congress Center

Vienna, Austria

Date: 4-8th July 2006

Tel. (+43/1) 53116 - 38

Fax: $(+43 / 1) 53116-61$

e-mail: azmedinfo@media.co.at 


\section{Fruit teas damage dentine}

Studies have shown that fruit teas erode dental enamel but, until now, the effect of these teas on dentine has been unknown. Now, a study published in the January edition of the Journal of Dentistry, shows that fruit teas remove the protective smear layer, opening up the dentinal tubules more fully, potentially making exposed dentine more sensitive. The erosive potential ( $\mathrm{pH}$ and neutralisable acidity) of a variety of Twining infusion fruit teas - including lemon, pear and guava, and 'blackcurrent

burst' - was assessed by
researchers at the Dental School
at the Wales College of Medi-
cine in Cardiff. Smeared den-
tine specimens were prepared
from extracted teeth and the
ability of each tea to remove the
smear layer was assessed by
measuring the diameter and
area of the opened tubules and
counting the number of patent
tubules seen under a micro-
scope. All the fruit teas tested
were highly acidic and able to
remove the smear layer.

\section{Police investigation}

On Tuesday 1 November 2005 Dorset Police were called to a derelict house in the Westbourne area of Bournemouth where workmen clearing the site for redevelopment uncovered the skeletal remains of an adult male in deep undergrowth. A full set of teeth were present and they appeared to have had extensive dental work.

Enquiries to formally identify the remains are on-going and Detective Sergeant Dave James of the Dorset Police Major Crime Investigation Team is very keen to track down the dental records of a John Neville Portlock (born 30th August 1954). Mr Portlock was brought up in the Hammersmith area of London and is also known to have resided in the following areas: High Wycombe, Weymouth, Swanage and Bournemouth. The last known sighting of Mr Portlock was in late 2001.

DS James would ask that surgeries check their patient database for Mr Portlock and in the event of a positive result contact him on 01202222291 . The requisite data protection form will then be forwarded for the release of the records.

Detective Sergeant 764 Dave James, Dorset Police, Major Crime Investigation Team, Bournemouth Police Divisional Headquarters, Madeira Road, Bournemouth, BH1 1QQ.

\section{Murder enquiry Torquay}

In 2001 Saraya Broadhurst (also known as Saraya Towfighi or Towfigi) went missing from her home in Torquay, Devon. On 7 November 2005, following information from local residents, an excavation was carried out at the address from which Saraya went missing. Human remains of a white female were discov-

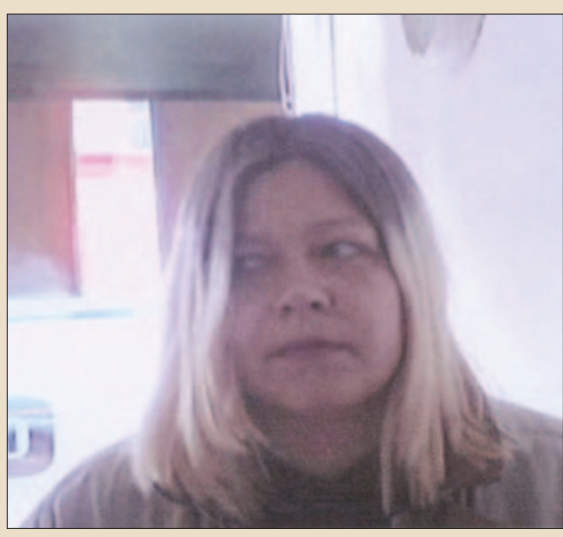
ered buried in the garden of this address. Attempts to identify Saraya's dentist have to date proved negative. It is urgently requested that dentists check their records and, if Saraya was ever registered at their practice, contact Detective Sergeant Ivor Lloyd of Devon and Cornwall Police on tel. 01803 841244. It is known that Saraya lived in Torbay, London and Brighton in the recent past, before her disappearance. The case is being treated as a murder enquiry. Saraya was born on 15 December 1962 .

\section{Tooth loss and heart disease linked, even among non-smokers}

There is a strong, progressive association between tooth loss and heart disease according to a report in the latest issue of American Journal of Preventive Medicine. The researchers found that heart disease was present in $4.7 \%$ of those without tooth loss, 5.7\% of those with one to five missing teeth, 7.5\% of those with six to 31 missing teeth, and $8.5 \%$ of those with total tooth loss. This finding emerged after adjusting for sex, race and ethnicity, education, marital status, diabetes, smoking status, alcohol consumption, high blood pressure, high blood cholesterol and body mass index. The researchers, based at the Division of Adult and Community Health at the Centers for Disease Control and Prevention in America, analysed data from 41,891 respondents aged 40 to 79 . The investigators noted that the results of this study are consistent with previous studies that link periodontal disease and tooth loss to an increased risk of atherosclerosis and heart attack. However, they said that other studies had not shown an association between oral conditions and heart disease. Catherine Okoro, the lead investigator, emphasised that the correlation between tooth loss and heart disease held even when smoking status was considered. 'Smoking has strong relationships to both tooth loss and heart disease. Nonetheless, when we stratified by age group and smoking status, a significant association remained between tooth loss and heart disease among respondents aged 40 to 59 years who had never smoked.' Okoro said the relationship between tooth loss and heart disease is of considerable public health interest because of the prevalence of both conditions in the general population. 'These results highlight the importance of health promotion counselling that includes the promotion of heart-healthy behaviours, the prevention and control of cardiovascular disease risk factors and the maintenance of good oral health,' she said.

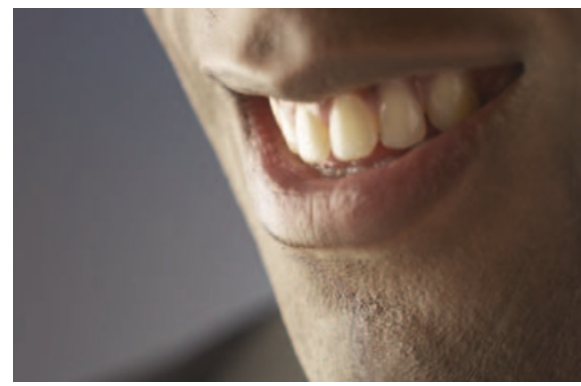

